\title{
Gastro-intestinal parasites in yearlings of wild Polish primitive horses from the Popielno Forest Reserve, Poland
}

\author{
K. SLIVINSKA ${ }^{1}$, J. GAWOR ${ }^{2}$, Z. JAWORSKI ${ }^{3}$
}

\begin{abstract}
${ }^{1}$ Schmalhauzen Institute of Zoology, National Academy of Sciences of the Ukraine, vul. B. Khmelnitskogo 15, Kyiv, Ukraine 01601, E-mail: horsecez@gmail.com; ${ }^{2} \mathrm{~W}$. Stefanski Institute of Parasitology of Polish Academy of Sciences, ul. Twarda, 51/55, 00-818 Warsaw, Poland; ${ }^{3}$ University of Warmia and Mazuria, ul. Prawocheńskiego 2,
\end{abstract}

10-720 Olsztyn, Poland

\begin{abstract}
Summary
To evaluate the gastro-intestinal parasite fauna of the wild Polish primitive horses (Equus caballus gmelini Ant., forma silvatica Vet.), 11 yearlings captured in the Reserve according to the control rules of population dynamics were diagnostically dewormed with abamectin+praziquantel. Expelled parasites were collected from the faeces 24, 36 and 48 hours after treatment. Among a total of 4456 specimens (a mean 405.1 per horse) 27 nematode species, one cestode and one species of botfly larvae were recovered. Strongylids were $100 \%$ prevalent and represented by 24 species ( 2 large strongylid and 22 cyathostome species). Five cyathostome species (Cylicodontophorus bicoronatus, C. insigne, Poteriostomum imparidentatum, Parapoteriostomum mettami and Gyalocephalus capitatus) were recorded for the first time in Polish primitive horses, whereas two species (Cyathostomum montgomeryi and Cylicostephanus bidentatus) were found for the first time in the horse in Poland. Oxyuris equi was found in $100 \%$ and Parascaris equorum in $63.6 \%$ of yearlings surveyed. Tapeworms (Anoplocephala perfoliata) were revealed in $72.7 \%$, while Gasterophilus intestinalis instars in $90.9 \%$ of horses. At least three parasite species were highly prevalent (i.e. S. vulgaris, A. perfoliata and G. intestinalis), which might be a reason of serious abdominal disorders in Polish horses living freely in the reserve.
\end{abstract}

Key words: gastro-intestinal parasites; wild Polish primitive horse; Popielno Forest Reserve

\section{Introduction}

The Polish primitive horse (Equus caballus gmelini Ant., forma silvatica Vet.) is a subspecies of wild horse, which had lived on the steppes of the southeast of Europe and Asia (Western Siberia). By the end of the $19^{\text {th }}$ century the original breed was completely extinct. In 1955 primitive horses that bore a strong resemblance to their wild ances- tors found in small farms of eastern Poland had been saved as a primitive breed of domestic horse (Equus caballus L.) in the Popielno Forest Reserve situated on the peninsula in the region of Great Mazurian Lakes, the north of Poland. The reserve currently embraces 1600 hectares of forest inhabited by three herds of horses (three stallions with mares and foals), which live there under natural conditions. No anthelminthic treatment has been applied to date to these horses. For the control of the population dynamics of herds, yearlings have been captured in the Reserve each year in early spring. Captured foals are kept in a stable to become tame. Forest horses spend the whole year in the reserve. Stallions mate mares, foals are born and the wild herd occupy and protect their territory. These horses are in good health condition. They are well known for their strong resistance to diseases of the alimentary tract and respiratory systems and they have no reproduction system disorders. Polish primitive horses are perfectly adapted to the natural environment and climate. Among factors, which may influence the health of these horses parasitic infections are of great importance in both young and adult ones. Investigations of parasite diversity, prevalence and intensity of infestation is therefore important for prognosis of herd condition.

To date little is known about gastro-intestinal parasite fauna of the wild Polish primitive horse. In previous studies their parasite infections were evaluated only on the basis of faecal examination (Romaniuk et al., 2001; Gawor, 2000) or limited data on strongyles were obtained from stabled horses, as fauna of only two Polish primitive horses has been investigated based on diagnostic anthelmintic treatment (Gawor, 2000). Hence, there are no data on gastro-intestinal parasites of the wild Polish primitive horses from the reserve.

In this study, gastro-intestinal parasites of wild yearlings captured in the Reserve were collected using the technique of diagnostic deworming (Kuzmina et al., 2005). Compari- 
son of the results with those obtained previously from free ranged Przewalski horses in Chornobyl Exclusion Zone (Slivinska et al., 2006) is the basis for ecological management of the parasitological situation in free-living horses.

Table 1. Results of faecal egg counts and number of isolated gastrointestinal parasites in the wild Polish primitive horses $(n=11)$ in the Popielno Forest Reserve, 2007

\begin{tabular}{cccc}
\hline Foal & \multicolumn{2}{c}{ EPG } & $\begin{array}{c}\text { Number of } \\
\text { isolated } \\
\text { specimens }\end{array}$ \\
\cline { 2 - 3 } Strongylidae & $\begin{array}{c}\text { Parascaris } \\
\text { equorum }\end{array}$ & specim \\
2 & 550 & 25 & 586 \\
3 & 250 & 25 & 263 \\
4 & 175 & 50 & 351 \\
5 & 400 & 25 & 498 \\
6 & 100 & 0 & 408 \\
7 & 50 & 25 & 490 \\
8 & 250 & 25 & 264 \\
9 & 225 & 25 & 336 \\
10 & 50 & 0 & 283 \\
11 & 275 & 0 & 392 \\
\hline Mean & 400 & 0 & 585 \\
\hline
\end{tabular}

\section{Material and Methods}

11 yearlings were captured in February 2007 in the Popielno Forest Reserve according to the control rules of population dynamics. No anthelminthic treatment has been applied to them prior to the survey. During the study the horses were kept in a stable. The faecal samples were examined for the egg counts using the McMaster technique (Herd, 1986) the day before deworming. Diagnostic treatment was applied in April with abamectin (4 mg) + praziquantel $(50 \mathrm{mg})$ (Abamitel-Plus paste, Krka, Slovenia) in a dose of $1 \mathrm{ml}$ per $20 \mathrm{~kg}$ b.w. Faecal sampling for expelled parasites (200 $\mathrm{g}$ of faeces in each sample) was performed 24, 36 and 48 hours after deworming (Osterman Lind et al., 2003; Kuzmina et al., 2005). A total of $600 \mathrm{~g}$ faeces were collected from each horse.

In the laboratory, samples were washed with tap water and preserved in $40 \%$ alcohol. Parasites were isolated from the faeces, fixed in $70 \%$ alcohol, counted and identified to the species level using the keys of Lichtenfels et al. (2008).

The mean number of gastro-intestinal parasites specimens per horse was 405.1 (ranged from 263 to 586). A total of 4456 specimens from examined horses were collected and identified (Table 1).

\section{Results}

According to the results of faecal egg counts, all horses (100\%) were found to be infected with strongylids (a mean EPG 247.7) and seven (63.6\%) with ascarids (a mean EPG 28.6) (table 1). After deworming, 29 gastro-intestinal parasite species were recovered from the yearlings surveyed. The parasite community comprised of 27 species of nematodes from four families (Strongylidae, Oxyuridae, Ascaridae, Habronematidae), one cestode species (Anoplo- cephala perfoliata) and one species of botfly larvae (Gasterophilus intestinalis). Strongylidae were represented by 24 species which belonging to the subfamily Strongylinae (two species) and Cyathostominae (22 species). Cyathostomum catinatum, C. pateratum, Coronocyclus coronatus, Cylicostephanus calicatus, C. minutus, C. longibursatus, C. goldi, Cylicocyclus nassatus and C. ashworthi occurred in all horses surveyed. The prevalence of Strongylus vulgaris, Triodontophorus serratus, Coronocyclus labiatus, Cylicocyclus insigne, and C. leptostomum was $81.8 \%-90.9 \%$. Ten cyathostomine species (Cyathostomum montgomeryi, Coronocyclus labratus, Cylicostephanus bidentatus, Cylicocyclus elongatus, C. ultrajectinus, Cylicodontophorus bicoronatus, Parapoteriostomum euproctus, $P$. mettami, Poteriostomum imparidentatum and Gyalocephalus capitatus) were less prevalent (9.1 \% $45.5 \%$ ). Oxyurids (Oxyuris equi) were recorded in $100 \%$ and ascarids (Parascaris equorum) in $63.6 \%$ of horses (Table. 2).

In general the intensity of infection was low. The mean number of specimens of a given species from the subfamily Strongylinae varied from 1.9 to 2.5 , while from Cyathostominae 1.0 - 134.7. Two the most abundant cyathostomins species (C. catinatum and $C$. nassatus) made up $70.8 \%$ of total strongylid population in horses examined. The mean number of specimens of $C$. catinatum and $C$. nassatus was 134.7 and 131.0, respectively per horse, while less than 22.5 specimens in case of the remaining 20 small strongyle species. Other parasite families were represented by single species. The mean number of oxyurids was 23.1 and ascarids 2.3. Tapeworms (Anoplocephala perfoliata) were recorded in $72.7 \%$ of horses, with a mean intensity 1.8 ( $1-4$ specimens). The prevalence of botfly larvae $(G$. intestinalis) was $90.9 \%$, with a mean 5.3 (1 13) instars per horse (Table 2).

\section{Discussion}

A total of 22 Cyathostominae species were recorded in the wild Polish primitive horses (yearlings) in this study, whereas 12 of such species were recorded in the previous study in such horses (two adults surveyed) living under stable conditions (Gawor, 2000). In brood horses (E. caballus) surveyed in Poland, a total of 23 Cyathostominae species were recorded (Gawor, 1995) (table 3). Cyathostominae species such as Cylicodontophorus bicoronatus, Cylicocyclus insigne, Poteriostomum imparidentatum, Parapoteriostomum mettami and Gyalocephalus capitatus were recorded for the first time in the Polish primitive horses. It is important to point out that two cyathostome species, Cyathostomum montgomeryi and Cylicostephanus bidentatus were recorded for the first time in the wild and brood horses (E. caballus) in Poland.

The present results are similar to those obtained in the earlier study of Przewalski horses under natural conditions in the Chornobyl Exclusion Zone (CEZ), Ukraine (Slivinska et al., 2006). Characteristics of area and climatic conditions for Przewalski horse and Polish primitive horse are 
Table 2. Results of gastro-intestinal parasite survey in the wild Polish primitive horses $(\mathrm{n}=11)$ in the Popielno Forest Reserve, 2007

\begin{tabular}{|c|c|c|c|c|c|c|}
\hline \multirow[t]{2}{*}{ Parasite species } & \multirow{2}{*}{$\begin{array}{c}\text { Prevalence } \\
(\%)\end{array}$} & \multicolumn{4}{|c|}{ Intensity of infection } & \multirow{2}{*}{$\begin{array}{c}\text { Total number } \\
\text { of specimens founc }\end{array}$} \\
\hline & & Mean & Min. & Max. & $\mathrm{SD}$ & \\
\hline \multicolumn{7}{|l|}{ Strongylinae } \\
\hline S. vulgaris & 81.8 & 1.9 & 1 & 3 & 0.78 & 17 \\
\hline Triodontophorus serratus & 90.9 & 2.5 & 1 & 6 & 1.72 & 25 \\
\hline \multicolumn{7}{|l|}{ Cyathostominae } \\
\hline Cyathostomum catinatum & 100.0 & 134.7 & 58 & 225 & 60.05 & 1482 \\
\hline C. pateratum & 100.0 & 13.0 & 1 & 29 & 7.66 & 143 \\
\hline C. montgomery & 9.1 & 5.0 & 5 & 5 & 0.0 & 5 \\
\hline Coronocyclus coronatus & 100.0 & 9.8 & 2 & 18 & 4.85 & 108 \\
\hline C. labiatus & 90.9 & 4.7 & 1 & 14 & 3.86 & 47 \\
\hline C. labratus & 45.5 & 1.0 & 1 & 1 & 0.0 & 5 \\
\hline Cylicodontophorus bicoronatus & 45.5 & 1.0 & 1 & 1 & 0.0 & 5 \\
\hline Cylicocyclus ashworthi & 100.0 & 13.2 & 3 & 28 & 7.94 & 145 \\
\hline C. elongatus & 27.3 & 1.0 & 1 & 1 & 0.0 & 3 \\
\hline C. insigne & 90.9 & 7.3 & 1 & 16 & 4.85 & 73 \\
\hline C. leptostomum & 90.9 & 4.6 & 1 & 8 & 2.55 & 46 \\
\hline C. nassatus & 100.0 & 131.0 & 52 & 193 & 41.7 & 1441 \\
\hline C. ultrajectinus & 9.1 & 3.0 & 3 & 3 & 0.0 & 3 \\
\hline Cylicostephanus calicatus & 100.0 & 5.3 & 2 & 12 & 3.22 & 58 \\
\hline C. minutus & 100.0 & 10.2 & 2 & 20 & 5.62 & 112 \\
\hline C. longibursatus & 100.0 & 22.5 & 16 & 36 & 6.50 & 247 \\
\hline C. goldi & 100.0 & 11.9 & 7 & 21 & 4.35 & 131 \\
\hline C. bidentatus & 27.3 & 1.7 & 1 & 2 & 0.58 & 5 \\
\hline Poteriostomum imparidentatum & 9.1 & 1.5 & 1 & 2 & 0.71 & 2 \\
\hline Parapoteriostomum mettami & 9.1 & 1.0 & 1 & 1 & 0.0 & 1 \\
\hline P. euproctus & 9.1 & 4.0 & 4 & 4 & 0.0 & 4 \\
\hline Gyalocephalus capitatus & 36.4 & 1.3 & 1 & 2 & 0.50 & 5 \\
\hline \multicolumn{7}{|l|}{ Ascaridae } \\
\hline Parascaris equorum & 63.6 & 2.3 & 1 & 6 & 1.80 & 16 \\
\hline \multicolumn{7}{|l|}{ Oxyuridae } \\
\hline Oxyuris equi & 100.0 & 23.1 & 11 & 43 & 9.39 & 254 \\
\hline \multicolumn{7}{|l|}{ Habronematidae } \\
\hline Habronema spp. & 18.2 & 3.0 & 2 & 4 & 1.41 & 6 \\
\hline \multicolumn{7}{|l|}{ Anoplocephalidae } \\
\hline Anoplocephala perfoliata & 72.7 & 1.8 & 1 & 4 & 1.65 & 14 \\
\hline \multicolumn{7}{|l|}{ Gasterophilidae } \\
\hline Gasterophilus intestinalis & 90.9 & 5.3 & 1 & 13 & 4.0 & 53 \\
\hline
\end{tabular}

similar in both reserves, in Poland and Ukraine. A total of 29 gastro-intestinal parasite species were recorded in Polish primitive horses in this study in comparison with 33 of such species found in Przewalski horses in the CEZ. A mean number of large strongylids (Strongylinae) varied from 1.9 to 2.5 in this study and 1.0 to 3.3 in Przewalski horses in the CEZ, while cyathostomes from 1.0 to 134.7 and 1.0 to 88.2 in this study and in the CEZ, respectively. The prevalence of Strongylus vulgaris in Polish primitive horses from the reserve was $81.8 \%$. The earlier study of horses from the Popielno Reserve reported also high prevalence of large strongylids, with Strongylus vulgaris being dominant in horses from the reserve $(66.7 \%)$ (Gawor, 2000). The most abundant cyathostome species in two stabled Polish horses was $C$. catinatum $(74.7 \%$ of small strongyle population) (Gawor, 2000), which is similar to the present results, but on the contrary to our data $C$. nas- satus in the previous investigations was much less plentiful $(4.8 \%)$. This difference might be a reason of anthelmintic treatment which has been given to the stabled horses each year. In both, Przewalski and Polish primitive horses the dominant gastro-intestinal parasites were strongylids. However, Oxyuris equi, Anoplocephala perfoliata and Gasterophilus intestinalis were also highly prevalent in both groups of examined animals. In general the higher diversity of cyathostome species with the lower intensity of infection was observed in Polish primitive horses from the reserve when compare with riding horses. Osterman Lind et al., (2003) and Kuzmina et al., (2005), using the same method of diagnostic deworming, found 15 and 19 cyathostome species, respectively, despite the fact that they investigated a larger number of horses than in the present study, namely 27 in Sweden and 44 in Ukraine.

Our findings that a few strongylid cyathostome species 
Table 3. Species of Cyathostominae found in horses in Poland

\begin{tabular}{|c|c|c|c|}
\hline Species & Present study & $\begin{array}{c}\text { Polish primitive } \\
\text { stabled horses }(\mathrm{n}=2) \\
(\text { Gawor, } 2000)\end{array}$ & $\begin{array}{l}\text { Brood horses }(\mathrm{n}=50) \\
\quad(\text { Gawor, 1995) }\end{array}$ \\
\hline Cyathostomum catinatum & + & + & + \\
\hline C. pateratum & + & + & + \\
\hline C. montgomeryi & + & - & - \\
\hline Coronocyclus coronatus & + & + & + \\
\hline C. labiatus & + & + & + \\
\hline C. labratus & + & + & + \\
\hline Cylicodontophorus bicoronatus & + & - & + \\
\hline Cylicocyclus radiatus & - & - & + \\
\hline C. ashworthi & + & + & + \\
\hline C. elongatus & + & + & + \\
\hline C. insigne & + & - & + \\
\hline C. leptostomum & + & + & + \\
\hline C. nassatus & + & + & + \\
\hline C. ultrajectinus & + & - & $-*$ \\
\hline Cylicostephanus calicatus & + & + & + \\
\hline C. minutus & + & + & + \\
\hline C. hybridus & - & - & + \\
\hline C. longibursatus & + & + & + \\
\hline C. goldi & + & + & + \\
\hline C. asymetricus & - & - & + \\
\hline C. bidentatus & + & - & - \\
\hline Petrovinema poculatum & - & - & + \\
\hline Poteriostomum imparidentatum & + & - & + \\
\hline P. ratzii & - & - & + \\
\hline Parapoteriostomum mettami & + & - & + \\
\hline P. euproctus & + & - & $-*$ \\
\hline Gyalocephalus capitatus & + & - & + \\
\hline Number of species & 22 & 12 & 23 \\
\hline
\end{tabular}

constitute the bulk of the gastro-intestinal community in the wild Polish primitive horse are confirmed by results of helminth surveys conducted in various breeds of domestic horses in other countries, i.e. Great Britain (Ogbourne, 1976), Spain (Meana et al., 2004), the Netherlands (Eysker \& Mirck, 1986), Hungary (Farkas, 2004), Poland (Gawor, 1995, Romaniuk et al., 2001), Australia (Mfitilodze \& Hutchinson, 1990), USA (Reinemeyer et al., 1984; Lyons et al., 1997) and South Africa (Scialdo-Krecek, 1983). Similar results were obtained also from Asiatic equids, Turkmen kulans (Equus hemionus Pallas, 1775) in the Ukraine and Turkmenia (Dvojnos et al., 1992). It is important to point out that a majority of 29 gastro-intestinal species recorded in Polish primitive horses from the reserve are of veterinary importance. The larval stages of cyathostomes can be harmful for horses in early spring causing winter cyathostominosis, while Strongylus vulgaris, Anoplocephala perfoliata and Gasterophilus intestinalis can be a reason of serious abdominal disorders all over the year. The high prevalence of large strongyles
(81.8\%), tapeworms $(72.7 \%)$ and botfly larvae (90.9 \%) in the wild Polish primitive horses constitutes the risk of colic with the potential of mortality. The technique of diagnostic deworming used in this study gives opportunity for detailed evaluation of gastro-intestinal parasite fauna in horses offering improvement of parasitological diagnosis. Diagnostic deworming is especially useful in cases when slaughter studies are not possible. This method has also been positively applied to assess cyatostome fauna in riding horses in Sweden (Osterman Lind et al., 2003) and Ukraine (Kuzmina et al., 2005), with even very rare species recovered. Dawson (2003) used "Modified Critical Treatment Method" for evaluation of anthelmintic efficacy against tapeworms and botfly larvae in horses. This procedure also relies on the collection and processing of faecal material containing expelled parasites from test animals. Therefore similarly to the method used in the present study provides a viable alternative to slaughter studies.

The present results revealed that at least three helminth species with potential for serious abdominal disorders are 
present in Polish primitive horses living freely in the reserve. Our findings suggest that anthelmintic treatment given to horses does not influence the small strongyle fauna diversity and prevalence of separate species, as the results obtained from untreated, free ranged horses are similar to those from regularly treated. However, the risk of colic due to $S$. vulgaris arterial larvae is still high in those not dewormed, with no such hazard in treated animals.

\section{Acknowledgements}

We would like to thank Mianowski Fund in Poland for financial support for the study and dr Zbigniew Wróblewski from the Veterinary Clinic in Pisz for his assistance in the organizing of the experiments.

\section{References}

DAWsON, K. (2003): A non-lethal method for assessment of efficacy of antiparasitics against parasites in horses such as Anoplocephala perfoliata and Gasterophilus intestinalis. Vet. Parasitol., 115: $67-70$

Dvojnos, G. M., Kharchenko, V. A., Zvegintsova, N. S. (1992): Characteristics of the helminth community from Turkmen kulan (Equus hemionus). Parasitologia, 26: 246 -251 (in Russian)

EYSKER, M., MIRCK, M. H. (1986): The distribution of inhibited early third stage Cyathostominae larvae in the large intestine of the horse. Zeitschr. Parasitenkd., 72: 815 - 820

FARKAS, R. (2004): The prevalence of equine gastrointestinal parasites in Hungary. Proc. IX Europ. Multicoll. Parasitol., Valencia, 18 - 23 July. p. 463 - 464

GAWOR, J. (1995): The prevalence and abundance of internal parasites in working horses autopsied in Poland. Vet. Parasitol., 58: 99 - 108

GAWOR, J. (2000): Occurence of Strongylidae (Nematoda: Strongyloidea) in Polish horses „tarpans” from Popielne Reserve. Wiad. Parazytol., 46: 87 - 92

HERD, R. P. (1986): Epidemiology and control of parasites in northern temperate regions. The veterinary clinics of North America: Equine Practice. Parasitology, 2: 337 - 355 Kuzmina, T. A., Kharchenko, V. A., Starovir, A. I., Dvojnos, G. M. (2005): Analysis of the strongylid nema- todes (Nematoda: Strongylidae) community after deworming of brood horses in Ukraine. Vet. Parasitol., 131: $283-290$

Lichtenfels, J. R., Kharchenko, V, A, Dvojnos, G. M. (2008): Illustrated identification keys to strongylid parasites (Strongylidae: Nematoda) of horses, zebras and asses (Equidae). Vet. Parasitol., 156: 4 - 161

Lyons, E. T., Tolliver, S. C., Collins, S. S., Drudge, J. H., Granstrom, D. E. (1997): Transmission of some species of internal parasites in horses born in 1993, 1994 and 1995 on the same pasture on a farm in central Kentucky. Vet. Parasitol., 70: 225 - 240

Meana, A., Olmeda, A. S., Pato, N. F., Diez, E., Felipe, M., MotA, J. (2004): Prevalence of mayor parasitic infections in free-ranging horses at Donana (Spain). Proc. IX Europ. Multicoll. Parasitol., 18 - 23 July. p. 463

Mfitilodze, M. W., Hutchinson, G. W. (1990): Prevalence and abundance of equine strongyles (Nematoda: Strongyloidea) in tropical Australia. $J$. Parasitol., 4: 487 - 494.

OgBourne, C. P. (1976): The prevalence, relative abundance and the site distribution of nematodes of the subfamily Cyathostominae in horses killed in Britain. $J$. Helminthol., 50: 203 - 214

Osterman Lind, E., Eysker, M., Nilsson, O., UgGla, A., HoGLund, J. (2003): Expulsion of small strongyle nematodes (cyathostomin spp) following deworming of horses on a stud farm in Sweden. Vet. Parasitol., 115: 289 - 99

Reinemeyer, C. R., Smith, S. A., Gabel, A. A., Herd, R. P. (1984): The prevalence and intensity of internal parasites of horses in the USA. Vet. Parasitol., 15: 75-83.

ROMANIUK, K., JAWORSKI, Z., SNARSKA, A. (2001): The occurence of internal parasites in the primitive Polish horses from forest breeding (in Polish). Medycyna Wet., 57: $204-206$

SCIALDO-KRECEK, R. C. (1983): Studies on the parasites of zebras 1. Nematodes of the Burchell's zebra in the Kruger National Park. Onderstep. J. Vet. Res., 50: $111-114$

SKŁADNIK, J. (1935): Trichoneminae u koni w Polsce. Wiad. Wet., 14: 137-183.

Slivinska, K., Dvojnos, G., KoPIJ, G. (2006): Helminth fauna of sympatric Przewalski's Equus przewalskii Poljakov, 1881 and domestic horses E. caballus L. in the Chernobyl exclusion zone, Ukraine. Helmintologia, 43: 27 - 32 